\title{
School-led Pre-service Teacher Education and Teacher Supply: Never Mind the Width, Feel the Quality
}

\author{
Jenny Gilbert \\ University of Bedfordshire, United Kingdom
}

\begin{abstract}
This paper tests the application of soft systems methodology (SSM) to a problem situation in an educational context. It reports the first stage of an international study of pre-service teacher education using the author's interpretation of the problem situation in order to determine the applicability of the approach. The international study compares the policy context and practice for the practicum element of pre-service teacher education within the three jurisdictions of England, UK, Ontario, Canada and New South Wales, Australia. A critical aspect of the international study is the commitment to use a methodology normally adopted in information systems and organisational management. The approach is primarily used as an action research tool but it can also be used to assist in sense making. In the trial application presented here it is being used for this second purpose. The methodology is described in some detail and the first three stages are then applied to the problem situation. Not only does the creation of root definitions highlight different perspectives but using SSM surfaces the likelihood of teacher shortages. This analysis has contrasted the government aim of improving the quality of teachers with the emerging issue of generating enough trained teachers in an environment where primary pupil numbers are set to grow by $20 \%$. The analysis to date provides a catalyst for discussion among partners and the identification of unintended consequences from multiple changes is characteristic of the application of SSM.
\end{abstract}

\section{Introduction}

Reporting the first stage of an international study of pre-service teacher education this paper uses the author's interpretation of the problem situation in order to determine how easy the approach is to apply and whether its output is useful. The international study itself is funded by the UK Higher Education Academy [1] and will compare the policy context and practice for the practicum element of pre-service teacher education within the three jurisdictions of England, UK, Ontario, Canada and New South Wales, Australia. A critical aspect of the international study is the commitment to use soft systems methodology (SSM), a methodology developed in organisational management and also adopted in Information Systems. While the approach is commonly used as an action research tool it can also be used to assist in sense making. This paper therefore rehearses and tests the application of SSM to a problem situation in an educational context.

The subject of this analysis will be the current situation in England driven by the recent introduction of an initiative entitled 'School Direct' that is described as school-led teacher education. This trial study utilises the author's experience within one university teacher education department to analyse the situation in order to judge the applicability of the methodology for the international study and to adapt where necessary and note any lessons learnt. The paper commences by exploring the purpose of the international study and the context within pre-service teacher education in England initiated by the publication of the White Paper, The Importance of Teaching [2] by the UK coalition government.

The research methodology will then be discussed in some detail and its relevance to the situation, and therefore its appropriateness, will be explored for this trial case study in England. This case will illustrate and test the methodology up to the start of stage 4 and through this shed light on the implications of the current policies on pre-service teacher educators' practice. The paper will conclude with a summary of the findings from the analysis and an assessment of the applicability of soft systems methodology.

\section{The international project}

The purpose of the international study is to share experience of the practicum element of pre-service teacher education between the three jurisdictions of England, Ontario and New South Wales in order to compare the policy landscape in each jurisdiction and its effect on the employability of pre-service teachers. The intention is also to inform government policy on teacher education, especially in the UK and to generate a set of principles for school/university partnerships to draw on when entering into agreements with schools in England, a model that may also be applied in different work based learning contexts. 
Government policy in the UK, and in many other countries, spells out the imperative for the education system to produce a workforce that allows the country to compete economically. PISA [3] league tables have become an indicator of each jurisdiction's educational success, enabling countries to compare themselves using the grades of 16 year olds in reading, mathematics and science. There are many recommendations in UK White Papers[2] to adopt selected aspects of the education system of countries that are high scoring in PISA, for example Finnish education and pre-service teacher education is regularly quoted, with no consideration of the significant differences between the two education systems. When adopting a systems paradigm one judges that introducing one aspect of a country's provision into a different system, and often an alien culture, will not necessarily give the same result. Cherry picking one idea from another jurisdiction, with no consideration of the whole context, cannot guarantee a specific impact.

\section{English context}

The White Paper The Importance of Teaching [2] published by the Conservative/Liberal Democrat coalition was followed by a more detailed report Training our next generation of outstanding teachers [4]. In this report a number of themes were headlined. Amongst these were the importance of raising the quality of entrants and the quality of teacher educators, the need to encourage career changers and to recruit more graduates to shortage subjects. An additional major proposal was the launch of "School Direct" [5] a system where schools apply for the trainee places and choose a provider to work with; they then select the trainees and on completion of the course the trainees would normally be expected to work in one of the schools within the group. Some of these initiatives have had limited impact on pre-service teacher education providers who for example were already demanding high entry grades from applicants. Some of the proposals have been followed with an implementation plan with incentives for applicants.

Whereas some of the themes, such as the need to recruit science, technology, mathematics and language teachers were continuations and extensions of the previous UK Labour government policy, a distinct shift can be perceived with the advent of the Coalition government's new school-led direction. Whitty [6] discusses the change in the teachers' role since the 1988 Education Reform Act stating that these changes had intensified under New Labour. This is a common pattern in English education where each government builds on the policies of the previous government. However, the school-led direction has been accompanied with much rhetoric from the Secretary of State on the value of learning alongside teachers in schools [7]. Given that in England secondary PGCE trainees already spend 24 weeks in schools and just 12 weeks in training courses, considerably longer than in most countries, the assertion that teacher training is not currently school based is galling. There has, however, been an increase of the minimum time that primary PGCE trainees must spend in schools rising from 90 to 120 days from September 2013.

Since 2011 change has been endemic and rapid, making it difficult for schools and universities to adapt and reach mutual agreement on how to operate this new system. One adaptation to improve the quality of entrants to the profession is that applicant must pass the English and Mathematics skills test [8] before they begin the course and they have only three opportunities to pass. If they fail three times they cannot retake the test for two years. This replaces the previous system where trainees had an indefinite number of opportunities and had to pass by the end of the course. No-one would deny that this is a sensible initiative but introduced it rapidly has led to many applicants becoming very stressed and failing the time constrained test. The evidence in the author's institution is that a very small proportion of post graduate applicants have been lost but up to $10 \%$ of undergraduate applicants have failed three times. As a result many universities are setting up support sessions to aid their applicants. One provider has found that using games training is more effective than further subject training as many applicants have problems responding at the speed needed.

Applicants for shortage subjects have been offered incentives in the form of generous bursaries if they hold good degrees. However, local evidence suggests that "School Direct" has still found it very difficult to recruit to these subjects while most universities have been able to recruit to their, now, lower targets in these subjects. One of the initiatives to encourage career changers is Troops to Teachers [9]. Six universities have been funded to work together on this initiative to offer a two year degree for ex-soldiers who have been recruited with equivalent prior learning to enter at year 2 level. The National College for Teaching and Leadership (NCTL) has set up Premier Plus [10] to support mature applicants and to work with schools to find a suitable place for them to gain the necessary experience for application for shortage secondary subjects.

So schools in England can now bid for teacher education places under the "School Direct" Programme [5] and specify which university, or other provider will accredit their pre-service teachers with Qualified Teacher Status. In addition to universities there have been other accredited providers in operation since the 1990s, School Centred Initial Teacher Training (SCITTs) formed by groups of schools or local authoritities. The lead 
school in School Direct can, in principle, specify how it wishes the course to operate although the university remains accountable to the regulator, Ofsted. Simultaneously, a new, tougher Ofsted [11] inspection regime has been introduced in the inspections of both schools and pre-service teacher education. Providers are no longer described as 'satisfactory', instead they are labeled as 'requiring improvement' and must either make speedy improvement or be summarily de-accredited. Other changes include the introduction of a new set of Teachers' Standards [12]. These standards are simplifications of the previous set and are also identical to those used to judge practicing teachers thus causing some uncertainty amongst school mentors as to whether the trainee has to reach an identical standard to that of an experienced teacher.

Whereas previously the grade of 'inadequate' has rung alarm bells and required significant intervention, now any provider graded 'requires improvement' will be re-inspected within the next year and will be de-accredited for all age phases if they do not reach 'good'. Whereas this could lead to a reduction in universities and SCITTs delivering pre-service teacher education, it is likely to be more than compensated for by the number of new SCITTs being accredited. Within the last year, 38 new SCITTs have been accredited [13].

Another significant change under the new framework is the statement within the Ofsted guidance document [11] that "All primary and secondary trainees awarded QTS exceed the minimum level of practice expected of teachers as defined by the Teachers' Standards by the end of their training'. Compliance with this statement is necessary for a provider to be judged either 'good' or 'outstanding 'and thus remain in operation! The use of the term all indicates that even one trainee graded 'requires improvement' could prevent a provider from being graded 'good'. In the early inspections in 2012/13, inspection teams were discussing trainees' performance with a view to seeing if there was evidence that any trainee would be graded 3 (requires improvement) at end of training. Of course it is difficult to predict trainee attainment accurately early in the year so providers were on firm ground challenging the team's predictive abilities. UCET NASBITT [14] published this guidance following advice from Ofsted. The focus of Ofsted inspections in the current round is system wide improvement. To that end the aspiration is that all trainees should achieve 'good' outcomes in their teaching by the end of their programme of training. This statement helps providers to explain away a few grade 3 trainees in this first year of operation providing they are tracking them and supporting them to make improvement. The impact of this change has been to make providers far more selective when choosing suitable trainees.

\section{Soft systems methodology}

The author has a background teaching Information Systems and has taught SSM which is an action research methodology that was initially used in organisational management and later in Information Systems [15]. In section 2 of this paper the danger of cherry picking ideas from elsewhere and parachuting them into an educational system was highlighted. The concept of a system or what Checkland [16] entitles a holon implies that we conconceptualise holistic entities where the whole is greater than the sum of the parts. Checkland uses the term 'holon' because the word 'system' is so widely used in general parlance that it has lost any precise definition and is often used to describe the real world in fairly loose ways whereas he posits that its value is not in labelling the real world but in systems thinking about the real world. Systems thinking encompasses a number of key concepts, the concepts of positive and negative feedback have implications that have been of particular value in electronic and mechanical systems. Cause and effect can be complex in situations where different components interact and this can lead to systemic effects often with unintended consequences. We are all familiar with this systems concept in relation to global warming and other environmental issues.

Systems also have emergent properties, i.e properties that exist within the holon but are not apparent within the individual components. A frequently quoted example is the creation of a bicycle from frame, pedals, wheels etc. the emergent property is its application as a means of transport, a property not demonstrated by the component parts. Another useful aspect of systems thinking is the definition of hierarchies. If any reader has had the author's experience they will relate to this example. As a student I understood computing at the top level of a business information systems application in an office, also at lower levels of programming down to one of the lowest levels where I could program in a low level language such as Assembler (although I have lost this ability over time) but despite understanding each level, I always felt that I couldn't 'find the stairs' between levels. I now realise that it is perceiving and using each level within the hierarchy that is important; a different scale is needed for each purpose so the concept of stairs is not an appropriate metaphor. A better analogy is a magnifying glass. In computing we use the convention of data flow diagrams, each drawn to represent a level with a numbering convention that enables recognition of an element at the lower or higher level. An example of hierarchies is the use of maps at different scales. If we want to see where Ontario and its towns and cities are within Canada we use a map that shows all of Canada. However, if 
we want to walk within Toronto we buy a street map of the city. Previously we had to purchase a series of maps at different scales and flip pages to adjust the scale. Since the advent of Google maps, we can open an ipad and reduce or enlarge the map using our fingers. However, we can still only concentrate on one level at a time. A better analogy than climbing stairs might be refocusing a microscope. The hierarchical model in the pre-service teacher education context would be government policy at a high level and pre-service teachers' experience at a lower level.

Checkland became involved in researching large scale technical projects where a 'hard' systems approach could produce a robust technical specification and a high quality product. But large scale projects, especially Information Systems, are renowned for not coming in on time, within budget and to quality standards. Problems surface in managing teams of people, managing customer expectation and dealing with the political dimensions of projects. Checkland aimed to derive a research method for such projects that was as rigorous as the positivistic paradigm applied in science research. He recognised that in social science research a quantitative approach was only possible with large scale data collection and even then cause and effect cannot necessarily be linked. He also recognised that human perceptions are important in Human Activity Systems and this led to the devising of SSM as a set of principles.

SSM allows stakeholders with multiple perspectives, objectives and perceptions to agree a common understanding across different policy, social and economic contexts, it also exposes unintended consequences of actions. In seeking a strong and sustainable school workforce, universities and schools need to agree what is needed to avoid the common mistake of setting out, with the best of intentions, to solve the wrong problem

\section{The seven stage model}

Figure 1 illustrates the 7 stage model of SSM. Checkland still draws his models by hand for two reasons, firstly to avoid the use of rectangles and straight lines that suggest a hard systems approach and a tightly defined process and secondly to accentuate the fluidity of the methodology driven by human interpretation. The figure below, however is the author's interpretation produced by using a drawing tool. We begin in the real world with Stage 1 , the recognition of a problem situation. In the example under discussion many universities worry that they will not have a large enough allocation of pre-service teachers to remain viable, and they cannot plan resources when the number of students studying a particular subject could change significantly from one year to the next. Coupled with this is the question of how they should approach, design and price 'School Direct'. Due to the complexity, the interacting factors and the differences in stakeholder perception there is no defined problem and the term problem situation should be used at this stage.

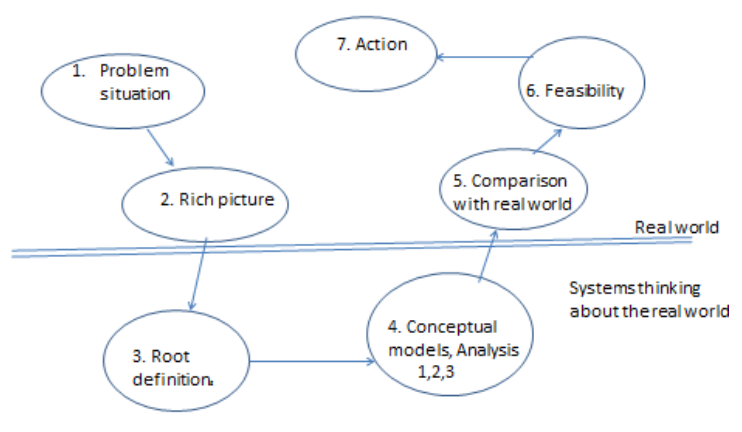

Figure 1. Seven stage model of SSM

In stage 2: the 'problem situation explained' the stakeholders produce a rich picture. The use of a diagram enables linkages to be shown more effectively and the use of pictures enables the affective aspects of the situation to be displayed; pictures often being a better way for exploring relationships. The rich picture both facilitates and captures the discussion within a group. Most importantly it presents the situation as a holon and can begin to show boundaries. The rich picture allows us to list alternative root definitions. Stages 1 and 2 are within the real world.

Stage 3 is the first stage within 'systems thinking about the real world'. In this stage we define the transformation that we want to take place and identify Customers, Actors, Transformation, Weltanschauung, Owner and Environment (CATWOE). This allows us to write alternative root definitions for the system. This stage can provide quite startling insight as one realises the number of ways the situation is perceived and can be defined. Stage 4, still in the systems thinking mode, uses three types of analysis. Analysis 1 considers the practical aspects, analysis 2 considers roles, norms and values and analysis 3 looks at the commodities that embody power. The final three stages are all within the real world. Stage 5 compares the analysis 1 model with the real world, Stage 6 considers whether this is feasible in the light of analysis 2 and 3 and finally Stage 7 is the action taken.

\section{Analysing the problem situation}

We begin to use SSM focusing on the first four stages of the methodology. SSM does not specify how the data should be collected, that level of detail is a decision for the researcher. For the main project 
three different stakeholder sets, teacher educators, teachers and pre-service teachers will form separate focus groups and discuss the problem situation with the researcher converting this into a rich picture. However, for this trial paper the rich picture was drawn up by the researcher following an informal group meeting with teacher educators. Figure 2 presents the rich picture as perceived by these University teacher educators and as interpreted by the researcher. It has not yet been tested with the original group. Although the context illustrated within the rich picture is described in section 3 it will be explored further here.

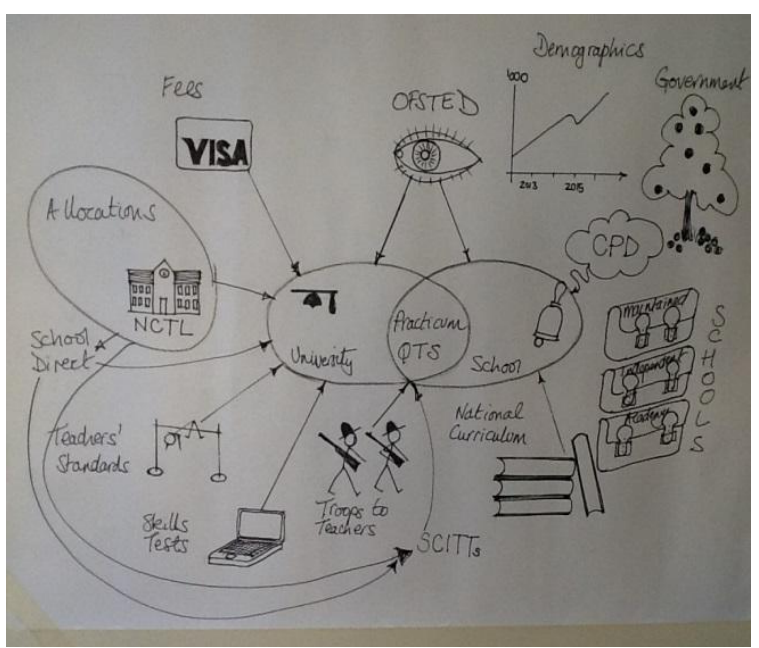

Figure 2. Rich picture of the problem situation

Foremost, overseeing schools and universities is the panoptican, the all seeing eye of Ofsted, the inspection regime. The other factors impacting on the system include the range of types of school now operating that universities work with, following the introduction in recent years of academies and free schools. These are schools funded directly by Government, rather than through local authorities, they are under slightly different regulatory frameworks, one key distinction being that they do not have to appoint qualified teachers. Many academies are joining together into federations, often presided by an Executive Head Teacher. Over the next two years there is a predicted $20 \%$ rise in primary numbers, coupled with this there is a rise in the school leaving age, rising to 17 from September 2013 and to 18 from September 2014 [17]. Another key change is the introduction of a new version of the National Curriculum with new assessment regimes. So schools are under the continuing pressure of externally imposed changes.

Meanwhile in UK pre-service teacher education, trainees now pay the full fee of $£ 9000$ per year, although as mentioned earlier there are bursaries for students in shortage subjects. The new set of Teachers' Standards together with a new Ofsted inspection framework demands that all pre-service teacher education providers graduating teachers reach a 'good' standard if the provider is to be graded 'good'. This raises the bar for students, illustrated in the rich picture by a high jump. The Mathematics on-line and English skills tests that preservice teacher education trainees have been required to pass before they graduate have been adapted in three ways. Firstly the pass level has been raised, secondly applicants have to pass before they can start the course and thirdly applicants are now permitted only three attempts. Previously, there was no cap on the number of attempts. The final and most significant factor within the problem situation is the introduction of School Direct. In 2011/12 the first small allocation of places to School Direct was made. These students completed their course in summer 2013. The allocation rose in 2012/13. It is difficult as yet to obtain national data on the success of recruitment of trainees to School Direct in 2012/13 but there is evidence that in most parts of England recruitment is less than $50 \%$. This underrecruitment is a significant concern. The NCTL are indicating that they will allocate up to $50 \%$ of places to school Direct in October 2013 for a start date of September 2014. If School Direct continues to recruit less well than universities this could exacerbate teacher shortages, especially as School Direct has recruited very poorly in shortage secondary subjects. It is not known by what factor, if any, NCTL might have over-allocated against expected demand for new teachers.

\section{Root definitions}

Within Stage 3 (figure 1), the first systems thinking stage, we develop root definitions utilising the CATWOE process. To test the method two root definitions have been developed and are described below. This case should exemplify what is meant by each category. By articulating the purpose of the system and what is the intended transformation we begin to conceive what can be done. We could develop many root definitions and then select the one with which most participants can agree. The two definitions below capture firstly a University centric transformation and secondly an alternative schoolbased perspective. This comparative approach helps to conceptualise the change to a school-led system.

Table 1. Root definitions

\begin{tabular}{|l|l|l|}
\hline & $\begin{array}{l}\text { Root } \\
\text { definition 1 }\end{array}$ & $\begin{array}{l}\text { Root } \\
\text { definition 2 }\end{array}$ \\
\hline $\begin{array}{l}\text { Customers } \\
\text { (Victims } \\
\text { beneficiaries) }\end{array}$ & $\begin{array}{l}\text { Pre-service } \\
\text { teachers }\end{array}$ & Schools \\
\hline
\end{tabular}




\begin{tabular}{|c|c|c|}
\hline Actors & $\begin{array}{l}\text { Teacher } \\
\text { educators } \\
\text { (academic } \\
\text { staff) \& } \\
\text { school } \\
\text { mentors }\end{array}$ & $\begin{array}{l}\text { Partner- } \\
\text { ship }\end{array}$ \\
\hline Transformation & $\begin{array}{l}\text { Untrained } \\
\text { applicants } \\
\text { converted to } \\
\text { 'good' } \\
\text { teachers }\end{array}$ & $\begin{array}{l}\text { Vacant posts } \\
\text { in a school } \\
\text { staffed by } \\
\text { 'good' } \\
\text { teachers }\end{array}$ \\
\hline $\begin{array}{l}\text { Weltanschauung } \\
\text { World view that } \\
\text { makes meaningful }\end{array}$ & $\begin{array}{l}\text { Both } \\
\text { practice and } \\
\text { theory } \\
\text { needed }\end{array}$ & $\begin{array}{l}\text { Rising pupil } \\
\text { numbers } \\
\text { and } \\
\text { shortage } \\
\text { subjects } \\
\text { create } \\
\text { concerns for } \\
\text { teacher } \\
\text { supply }\end{array}$ \\
\hline $\begin{array}{l}\text { Owner (can make } \\
\text { happen) }\end{array}$ & University & $\begin{array}{l}\text { Partner- } \\
\text { Ship }\end{array}$ \\
\hline $\begin{array}{l}\text { Environment } \\
\text { constraints }\end{array}$ & $\begin{array}{l}\text { Volatility of } \\
\text { school-led } \\
\text { model, } \\
\text { uncertain } \\
\text { numbers of } \\
\text { trainees and } \\
\text { associated } \\
\text { subjects }\end{array}$ & $\begin{array}{l}\text { Constant } \\
\text { change and } \\
\text { new } \\
\text { regulation }\end{array}$ \\
\hline
\end{tabular}

Using the above analysis we can now articulate each of the two root definitions.

Root definition 1: A university owned system using academic staff and school mentors to convert novices into 'good' newly qualified teachers by integrating theory and practice and operating within a volatile school-led pre-service teacher training environment.

Root definition 2: A partnership led system to generate 'good' newly qualified teachers to recruit into schools that are worrying about teacher supply and experiencing the continuing impact of change in government regulation.

Stage 4 involves us first selecting the most appropriate root definition and then considering the action needed to achieve it. Alternatively we may wish to achieve both transformations, where they are not in direct contradiction. This is Analysis 1. We would need more information in order to undertake Analysis 2, the analysis of roles, values, and norms. This stage recognises that these can be limiting factors or we may need adjustments. Finally in Analysis 3 we consider the commodities of power.
The most obvious one is the power resulting from the allocation of trainee numbers. Schools are allocated School Direct numbers first and then remaining numbers are allocated to universities and other providers. Providers graded 'outstanding' have been promised an allocation of the same number of trainees as the previous year. 'Good' providers will be allocated any places remaining. This could result in a university being given no allocation. Some schools are already exercising this power by asking universities to tender to deliver their course, making choices about who to work with based largely on price.

\section{Findings}

This paper aims to rehearse and test the application of SSM to the problem situation here presented, the introduction of school-led pre-service teacher training. At this point it is testing stages 1 to 4 with the emphasis on stages 1 to 3 . Generating the rich picture was fairly difficult to achieve during the focus group with respondents. Piloting the process has highlighted a number of issues. Firstly, one needs to give the group two or three questions so that participants are clear what they are trying to describe. Then the researcher can document the discussion by starting with a Venn diagram using a mind map approach with arrows and text. Images are probably best added after the bulk of the discussion. They are likely to be more relevant and dynamic if the respondents discuss them but they can be overlaid later by the researcher.

The author's original intention to ask the group to draw proved unsuccessful as few considered themselves sufficiently competent artists and the challenge of conceptualising and creating pictures detracted from the discussion. Ideally, the final rich picture should be tested with the group. If the focus group is recorded this gives the researcher the opportunity to generate the root definitions that $\mathrm{s} / \mathrm{he}$ hears being articulated. If one is using this methodology as the researcher was in this case as a 'sense making' operation then one could say that the two root definitions generated have proved the point that there are multiple ways to see the problem situation and that this exercise moved the researcher's perspective from root definition 1 to root definition 2. This leap impacts on one's perception of the situation and, should one decide to move to the action research stage, then sharing this root definition with university academics and with the school partners would provide a starting point for action. If one chooses to combine the two definitions i.e. if one believes that integration of theory and practice is necessary then again this will impact on the actions taken. 
Not only has the creation of root definitions called attention to different perspectives but using SSM has highlighted the danger of schools seeing a significant shortage of teachers. In effect this analysis has contrasted the government aims of improving the quality of teachers with the surfacing of the problem of generating enough trained teachers. Thus whilst there may be a demand for quality, when raising the bar for recruitment of pre-service teachers we need to be wary that we are not reducing the pool of trained teachers. Replacing them with unqualified teachers is a high risk strategy.

The surfacing of this unintended consequence of a number of parallel changes i.e. actions to improve quality could have a very significant impact on quantity, demonstrates a key concept within a systems approach. It therefore justifies the application of the methodology. Clearly some of the effects result from the introduction of new requirement and providers are already beginning to put in place actions to mitigate so that some of the aspects will prove to be only teething problems. For instance, once all providers give support and most applicants having an expectation regarding the skills tests, the failure rates on the tests should reduce. Similarly, the application system for School Direct has been separate from the core system and in addition to the confusion and uncertainty for applicants it has led to applicants being interviewed twice by the same provider with a considerable amount of poaching between universities, SCITTs and School Direct. An integrated application system is about to start and this should improve the situation although the response times required from schools is more demanding. Some schools are already passing recruitment over to their provider.

\section{Conclusions}

This paper has demonstrated that the first stages of SSM can deliver a valuable starting point. They can help in conceptualising the problem as a sense making activity. It is not possible to judge whether this will be successful for an action research approach. But it is a promising start. The analysis to date is an excellent catalyst for discussion among partners. The identification of the unexpected consequences of a number of changes is characteristic of the application of SSM. The analysis suggests that schools and providers will need to work together if they are to achieve the dual and, to some extent conflicting aims, of improving the quality of new teachers while also increasing the quantity.

\section{References}

[1] Higher Education Academy, http://www.heacademy.ac.uk/international-scholarshipscheme

[2] Department for Education, 2010 "The Importance of Teaching” White Paper. London: Stationery Office

[3] OECD Programme for International Studies (PISA) retrieved from http://www.oecd.org/pisa (Access date: 29 May 2013)

[4] Department for Education, 2011," Training our next generation of outstanding teachers: Implementation Plan", DfE-00038-2011

[5] Teaching Agency, 2012 "A guide to School Direct 2013/14", retrieved from http://www.education.gov.uk/schools/careers/trainingandd evelopment/initial/b00205704/school-

direct?cid=schooldirectinfo\&type=redirect (Access date: 29 May 2013)

[6] Gray S L and Whitty G (2010) "Social trajectories or disrupted identities? Changing and competing models of teacher professionalism under New Labour", Cambridge Journal of Education 40 (1) pp.5-23

[7] Gove M, 2012 Speech to National College, http://www.education.gov.uk/inthenews/speeches/a002103 08/michael-gove-at-the-national-college-annualconference

[8\} Department for Education, 2012, "Review of skills test"

http://www.education.gov.uk/schools/careers/trainingandd evelopment/professional/b00212154/introduction/review

[9] Department for Education, 2013 "Troops to teachers" http://www.education.gov.uk/childrenandyoungpeople/you ngpeople/militaryethos/a00216965/troops-to-teachers

[10] Department for Education, 2013 "Premier Plus" http://www.education.gov.uk/get-into-teaching/subjectsage-groups/why-sign-up

[11] Ofsted, 2012, "Initial Teacher Education (ITE) inspection handbook: for use from September 2012"

[12] Department for Education, 2012 "Teachers' Standards"

[13] Parliamentary Questions, 2013: Right Honourable David Laws MP, 22 April 2013

[14] UCET NASBITT, 2013 "Using the UCET NASBITT Guidance when grading trainees in the context of Ofsted inspections"

[15] Checkland P B and Holwell S, 1998, "Information, Systems and Information Systems: Making Sense of the Field", Wiley, London 
[16] Checkland P B, 1981, "System Thinking, Systems Practice", Wiley, London

[17 School Leaving Age, https://www.gov.uk/know-whenyou-can-leave-school. 